\title{
USO DE BICICLETA NAS CIDADES BRASILEIRAS DE PEQUENO PORTE: UMA CULTURA AMEAÇADA
}

\author{
Daniel Guth ${ }^{1}$ \\ Associação Brasileira do Setor de Bicicletas \\ Programa de Pós-Graduação em Urbanismo - PROURB \\ danielguth@gmail.com \\ Victor Andrade Carneiro da Silva ${ }^{2}$ \\ Universidade Federal do Rio de Janeiro \\ Faculdade de Arquitetura e Urbanismo (FAU/UFRJ) \\ victorandrade@fau.ufri.br
}

\begin{abstract}
Resumo
Este artigo apresenta uma ampla pesquisa exploratória realizada em dez cidades brasileiras de até 100 mil habitantes e com alto uso de bicicleta, buscando destacar os atributos sobre a tradicional cultura da bicicleta e correlacionar os efeitos da escalada de motorização de automóveis e motocicletas, no Brasil, sobre estas cidades e outras de mesmo porte. Os resultados apontam para intensas transformações nos hábitos de locomoção da população nestas cidades, com efeitos não apenas sobre o uso de bicicletas, através da migração modal, mas também sobre outras variáveis verificadas e que impactam a qualidade de vida nestas cidades.
\end{abstract}

Palavras-chave: Mobilidade urbana. Motorização. Bicicletas. Migração modal. Segurança viária.

\section{BICYCLE USE IN BRAZILIAN SMALL CITIES: A THREATENED CULTURE}

\begin{abstract}
This article presents an exploratory research carried out in ten Brazilian cities with less than 100 thousand inhabitants and with high bicycle use rates, in order to highlight the attributes about the traditional bicycle culture and to correlate the effects of automobiles and motorcycles growth in these cities and others of the same size. The results indicate intense changes regarding the travel behaviour of the population, with effects not only on bicycle use, through modal shift, but also on other variables that impact the quality of life in these cities.
\end{abstract}

Keywords: Urban mobility. Motorization. Bicycle use. Modal shift. Road safety.

\footnotetext{
${ }^{1}$ Coordenador de Projetos da Associação Brasileira do Setor de Bicicletas (Aliança Bike) e mestrando pelo Programa de Pós-Graduação em Urbanismo (PROURB/UFRJ).

${ }^{2}$ Prof. Dr. FAU/UFRJ e coordenador do Laboratório de Mobilidade Sustentável (LABMOB).
}

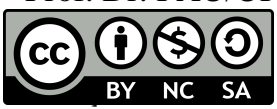




\section{INTRODUÇÃO}

A realidade de uso da bicicleta como meio de transporte, no Brasil, varia bastante na sua distribuição geográfica e possui características diferentes dependendo do porte das cidades. Apesar dos municípios de pequeno porte - com até 100 mil habitantes, segundo o IBGE representarem 94,43\% do total de municípios brasileiros, neles vivem apenas 43,5\% da população do país.

O número de viagens feitas por meios ativos de transporte - notadamente a pé e por bicicletas - cresce conforme o porte da cidade diminui. São as cidades de pequeno porte que elevam o índice de participação da bicicleta na divisão entre os meios de transporte, com índices que superam a casa dos dois dígitos e quando, na média, não mais de $4 \%$ dos brasileiros se movem de bicicleta (ANTP, 2016).

Em muitas cidades brasileiras a bicicleta ainda resiste por diversos motivos: a) as distâncias são menores nas cidades de pequeno porte, considerando a mancha urbana; b) são cidades que apresentam indicadores mais baixos de violência no trânsito, ainda que esta realidade esteja em transformação; c) a taxa de automóvel/habitante, nas cidades pequenas, é inferior às cidades de médio e grande portes, revelando a eficiência, rapidez e praticidade da bicicleta como meio de transporte; d) o contato com a bicicleta como meio de transporte, nas cidades de pequeno porte, se dá desde cedo, revelando-se uma cultura que permanece no imaginário e na prática da população.

Por outro lado, a motorização individual por automóveis e motocicletas tem crescido a cada ano no país, sendo que nas cidades de médio e grande porte ela já vem mostrando seus limites - físico, ambiental, social e econômico. Em que pese a importância dos grandes centros urbanos e regiões metropolitanas, no Brasil, terem concentrado a maior parte dos investimentos em estrutura para mobilidade, pelo fato de serem vetores de desenvolvimento e de maior atenção das políticas federais, são as cidades de pequeno porte que têm apresentado, nos últimos 15 anos, as mais altas taxas de crescimento da frota motorizada, estimuladas por fatores como melhoria na renda, facilidade de crédito, desonerações fiscais e barateamento de veículos motorizados, especialmente motocicletas, aos consumidores finais.

As duas dimensões [a cultura resiliente de uso de bicicletas e o crescimento da motorização, especialmente de motocicletas] nas cidades de pequeno porte - e suas fricções são os objetivos centrais desta pesquisa exploratória. Sobre o uso de bicicletas, o objetivo desta investigação é imergir nesta cultura, no entendimento desta cultura, buscando identificar o que 
faz com que as cidades de pequeno porte apresentem índices mais altos de uso de bicicleta e também os possíveis impactos do crescimento da motorização para esta cultura. Já sobre a motorização, o objetivo é compreender as mudanças que estão em curso nas cidades em decorrência deste fenômeno, especialmente da ascensão das motocicletas, e os custos sociais atrelados aos indicadores de violência no trânsito.

Os atributos associados à cultura da bicicleta ${ }^{3}$, analisando os dados disponíveis, nos instigam a edificar um cenário de acelerada mudança nas cidades de pequeno porte, impulsionadas pela popularização dos veículos motorizados nestas cidades, especialmente das motocicletas e motonetas. Trata-se, outrossim, de um fenômeno recente - dos últimos vinte anos, mais acentuadamente - e ainda pouco estudado. Para Vasconcellos (2013), pesquisando a produção acadêmica sobre motocicletas nas cidades brasileiras:

\begin{abstract}
"O banco de dissertações e teses da Capes, no campo genérico da engenharia de transportes e na denominação de "trânsito urbano" (excetuando-se trabalhos de saúde pública) registra apenas uma dissertação sobre as motocicletas, feita em 1996, dentro de um conjunto de 44 trabalhos sobre segurança de trânsito em geral". (Vasconcellos, 2013, p.51)
\end{abstract}

Para Vasconcellos, a produção acadêmica sobre os impactos da crescente motorização nas cidades brasileiras está concentrada, quase exclusivamente, no campo da saúde pública. O autor escancara, desta forma, um campo importante e necessário para se investigar à luz de outras áreas do conhecimento.

\footnotetext{
${ }^{3}$ Ainda que seja um desafio adotar uma perspectiva para o termo "cultura", especialmente nos dias de hoje, sua complexidade e abrangência também é intrigante. "Cultura" tem origem no latim e deriva da palavra "colo". De acordo com o historiador Alfredo Bosi (2008), "colo significava, na língua romana mais antiga, 'eu cultivo'; particularmente, 'eu cultivo solo"”. Ou seja, a acepção da palavra estava ligada ao mundo agrário. Agricultura, por exemplo, seria a "cultura do campo". A cultura, portanto, como "aquilo que deve ser cultivado", segundo Bosi, "era um modo verbal que tinha sempre alguma relação com o futuro". A terminação - ura - carrega a desinência de futuro, de projeto. Durante séculos a palavra "cultura" se manteve relacionada à sociedade agrária e à perspectiva de quem almejava trabalhar (cultivar) a terra. Após a conquista da Grécia pelos romanos, a palavra cultura passou a ser utilizada como sinônimo de Paideia - que significava desenvolvimento humano, ou o arcabouço de conhecimentos para se transmitir às crianças -, origem do sistema de formação ética da Grécia Antiga.
}

Ainda de acordo com Bosi, somente "a partir do primeiro século é que se encontram exemplos da palavra nessa acepção"

- Como um conjunto de ideias e valores intelectuais. O que aqui propomos, portanto, como narrativa para ancorar o que seria a "cultura da bicicleta" conserva as duas acepções de cultura: 1) como algo que deve ser cultivado; e 2) como desenvolvimento humano e transmissão de conhecimento e valores de uma geração para outra. Se a cultura do arroz é determinada por um conjunto de técnicas e cuidados com a terra que permitem que seu plantio se desenvolva, a cultura da bicicleta igualmente nasce, cresce, floresce e se perpetua como derivação de características de pessoas e suas relações

- Entre si e com o território. Se a cultura dos kayapós também é o conjunto de ideias e valores transmitidos de uma geração a outra, a cultura da bicicleta igualmente pode ser compreendida como um conjunto de ideias e valores transmitidos. 


\section{MÉTODOS}

A partir dos objetivos expostos anteriormente, a metodologia para sustentar a presente análise se utilizou de dados secundários e primários a partir de um conjunto de técnicas.

Para analisar o crescimento da motorização e o fenômeno das motocicletas nas cidades de pequeno porte, dados secundários disponíveis nos permitiram aprofundar a análise e realizar os recortes necessários para sustentá-la. As bases de dados de emplacamento de veículos motorizados do DENATRAN (Departamento Nacional de Transportes), desde 2001, foram combinadas com as bases do IBGE relativas à população (e expectativa de população) para cada munícipio, desde o Censo 2000. Para a análise relativa aos impactos da motorização nas cidades brasileiras, com foco nos acidentes de trânsito, as bases de dados por município do Ministério da Saúde (Sistema de Informação sobre Mortalidade) e os relatórios da Organização Mundial de Saúde (OMS) foram essenciais para condução e sustentação da análise.

O objetivo relacionado com o estado da arte e a proposição de uma análise mais aprofundada sobre a cultura da bicicleta nas cidades de pequeno porte revelou-se um desafio de alta complexidade em decorrência da ausência de dados sobre a mobilidade ativa neste perfil de cidade. Podemos destacar, de antemão, a importância das pesquisas aqui indicadas para o conhecimento da mobilidade ativa nestas cidades e em outras de mesmo porte, à luz de um cenário, como veremos, de mudanças sensíveis por conta do crescimento da motorização.

Esta pesquisa exploratória partiu de dez cidades com altos índices de uso de bicicleta, que foram selecionadas como estudo de caso representando distintos biomas brasileiros, não sendo permitido repetir a mesma unidade da Federação (UF) e tendo o porte - até 100 mil habitantes - como característica comum. Para cumprir esta etapa, um survey online foi aplicado nas redes de contato de quatro diferentes associações de ciclistas de abrangência nacional União de Ciclistas do Brasil (UCB), Bicicleta para Todos, Rede Bike Anjo e Aliança Bike contendo a pergunta "você conhece alguma cidade brasileira de pequeno porte com alto uso de bicicletas?" como norte e um formulário para preenchimento visando obter mais dados sobre as cidades indicadas.

Como resultado desta primeira etapa, mais de 300 respondentes indicaram 228 cidades diferentes em todo o país, sendo $57 \%$ na região Sudeste, $17 \%$ na Sul, $10 \%$ na Centro-Oeste, $8 \%$ na região Nordeste e $7 \%$ na Norte. Uma carta escrita pelos autores, juntamente com as quatro organizações que apoiaram a pesquisa, foi endereçada a todas as prefeituras destas 228 cidades 
contendo perguntas sobre: a) estimativa de viagens realizadas de bicicleta; b) existência de infraestrutura cicloviária; c) existência de bicicletarias na cidade; d) quantidade de bicicletários e suportes de bicicleta instalados na cidade; e) estimativa de número de bicicletas por habitante; entre outras.

Para se determinar as dez cidades para a pesquisa exploratória, foram consideradas cinco dimensões presentes no questionário enviado às prefeituras: percentual de viagens estimadas; presença de infraestrutura cicloviária; quantidade estimada de bicicletas por habitantes; presença de bicicletários e paraciclos na cidade; e o interesse do município pelo desenvolvimento de políticas para o uso de bicicletas.

As cidades que tiveram os resultados mais positivos nestas dimensões foram selecionadas e são as seguintes: Mambaí (GO), Tarauacá (AC), Tamandaré (PE), Antonina (PR), Gurupi (TO), Cáceres (MT), São Fidelis (RJ), Pedro Leopoldo (MG), Ilha Solteira (SP) e Pomerode (SC).

Definidas as dez cidades e considerando uma análise por triangulação quali-quantitativa, determinou-se o conjunto de dados e informações a serem coletados:

- Levantamento Socioeconômico;

- Contagem Volumétrica de Veículos;

- Pesquisa de caracterização de ciclistas;

- Pesquisa de Perfil de ciclistas.

A coleta de dados foi realizada durante os meses de Agosto e Novembro de 2017 por dezenas de pesquisadores locais, que contaram com voluntários e também, em alguns casos, com o apoio de equipes indicadas pela prefeitura local - seja dos departamentos de trânsito ou de secretarias afim, como Saúde e Meio Ambiente.

A metodologia da contagem volumétrica de veículos foi elaborada pelos autores com base em práticas já consolidadas no Brasil, com contadores físicos a partir de folhas de contagem considerando: quantidade e direção para cada veículo e dados gerais de caracterização de ciclistas, como sexo, idade, uso de capacete, tipos de bicicleta, entre outros. O horário das contagens é padronizado - entre $6 \mathrm{~h}$ e $20 \mathrm{~h}$ - exatamente para contemplar as viagens com motivo trabalho e escola. O local de contagem foi determinado como sendo a principal via da cidade, de uso misto do solo, com concentração de comércio, serviços e órgãos públicos.

Já a metodologia da Pesquisa de Perfil de Ciclistas foi elaborada pelo LABMOB Laboratório de Mobilidade Sustentável, do PROURB da Universidade Federal do Rio de Janeiro, em parceria com a ONG Transporte Ativo, do Rio de Janeiro. Com 2.109 entrevistas 
realizadas nas dez cidades de pequeno porte, os dados representam o maior levantamento sobre o perfil de quem usa bicicleta já realizado em cidades com este porte.

\section{O CRESCIMENTO DA MOTORIZAÇÃO NAS CIDADES DE PEQUENO PORTE ${ }^{4}$ : O FENÔMENO DAS MOTOCICLETAS}

Uma das transformações mais intensas que vêm ocorrendo nas cidades brasileiras, e que aqui destacamos, diz respeito ao crescimento da motorização da mobilidade e seus impactos. O Brasil, como é de conhecimento geral, incentivou a produção, montagem, aquisição e o uso de automóveis e motocicletas com intensidade a partir dos anos $1990^{5}$ e, em especial, durante a primeira décadados anos 2000.

O crescimento dos veículos motorizados no Brasil, entre 2003 e 2014, foi mais de dez vezes superior à variação do crescimento populacional e mais do que quatro vezes superior à variação de renda (Gráfico 1).

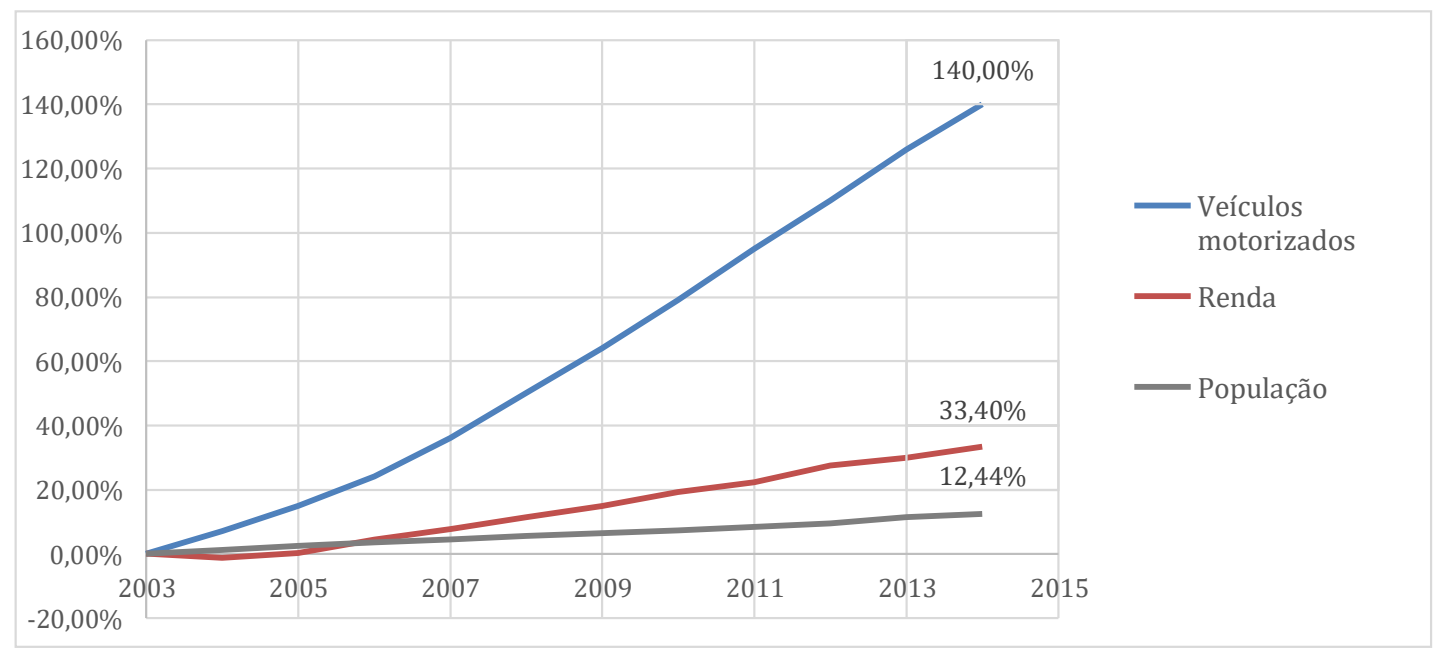

Gráfico 1. Evolução da renda, população e veículos motorizados (2003-2014), elaborado pelos autores Fontes: DENATRAN, IBGE

Algumas medidas engendradas pelo governo federal são importantes de serem destacadas, como: a) as políticas de estímulo à produção de motocicletas no final dos anos

\footnotetext{
${ }^{4}$ De acordo com o IBGE, o porte dos municípios é definido pela demografia, sendo os de pequeno porte de até 100 mil habitantes, os de médio porte entre 100 e 500 mil habitantes, e os de grande porte a partir de 500 mil habitantes.

${ }^{5}$ Com o processo de liberalização econômica e com a criação do Plano Real (1994).
} 
1990; b) a aprovação de produção de automóvel com mil cilindradas e os veículos flex em 2003 ; c) as políticas de desoneração tributária para o setor de motocicletas e automotivo, até os dias atuais; d) os subsídios à gasolina para conter elevação de seu custo; e) as facilidades de crédito para aquisição de automóveis e motocicletas; e f) o conjunto de infraestruturas e políticas públicas, em todas as cidades, voltadas para viabilizar a crescente motorização do país.

\begin{abstract}
"Com o apoio político e fiscal do governo federal a indústria automotiva no Brasil pôde abrir um novo ramo de negócios de grande significância. $\mathrm{O}$ aumento acelerado desta indústria foi apoiado inicialmente pela liberação da importação em 1991. Adicionalmente, o governo permitiu a formação de consórcios e de sistemas de financiamento que permitiam chegar a prestações mensais de $R \$ 150$. O governo federal criou, dentro dos dois maiores bancos públicos - Banco do Brasil e Caixa Econômica Federal, programas específicos de financiamento de motocicletas, com juros mais baixos. Um dos programas tinha uma propaganda que ligava a aquisição da motocicleta à "libertação" da pessoa da necessidade de usar o transporte coletivo" (Vasconcellos, 2013, p.13).
\end{abstract}

Todo este emaranhado de medidas, políticas públicas, e suas consequências foram sentidas e absorvidas nas cidades brasileiras de todos os portes, em todas as regiões. O crescimento excepcional de motocicletas, motonetas e ciclomotores, nos últimos 15 anos, é um dos fenômenos que aqui destacamos.

Gráfico 2. Número de motos, motonetas e ciclomotores no Brasil entre 2001 e 2016.

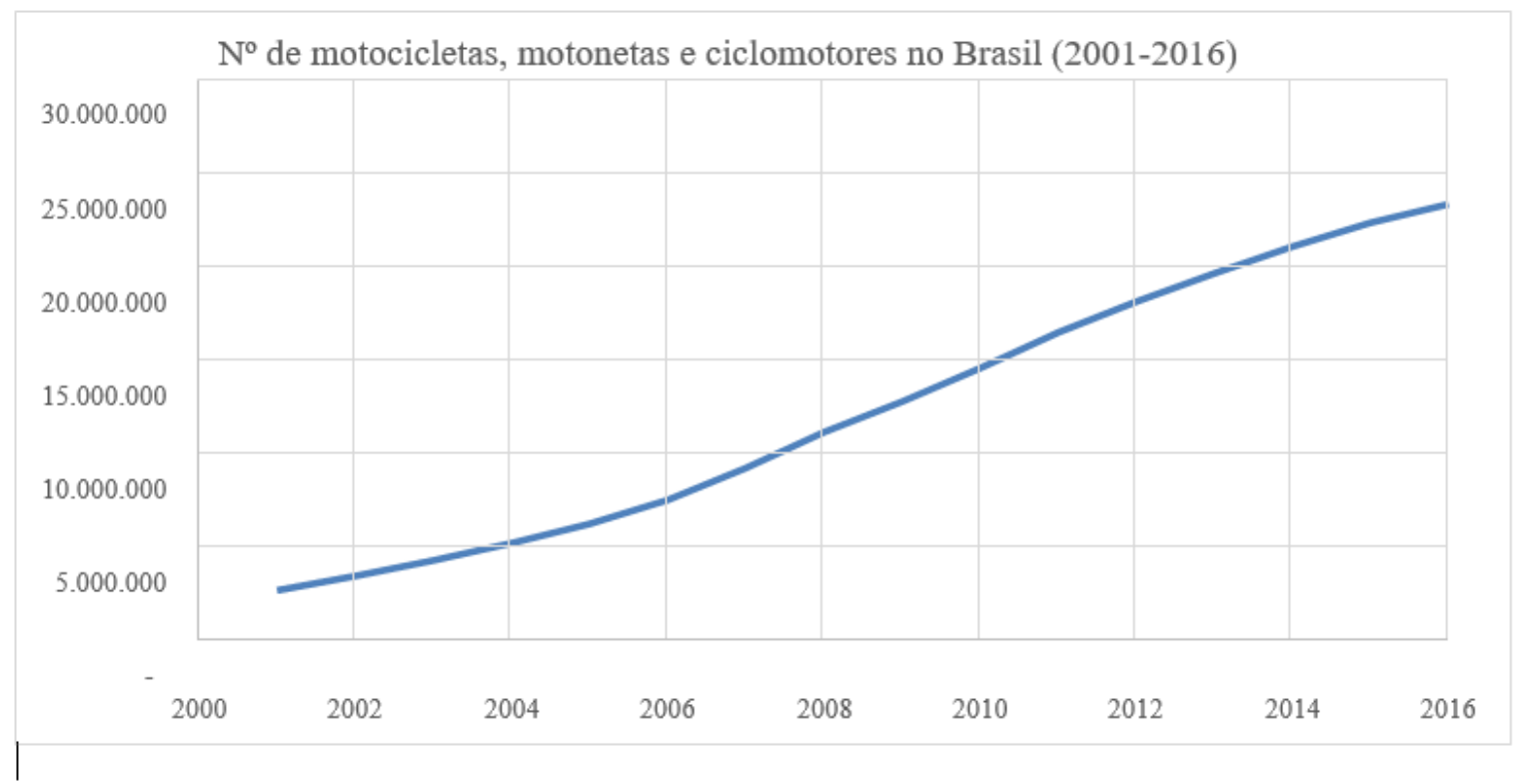

Fonte: elaborado pelos autores a partir de dados do DENATRAN

Se analisarmos a divisão modal por porte de cidade, veremos que os municípios de pequeno porte são os que concentram as mais altas taxas de viagens por modos ativos de 
deslocamento, como o uso de bicicleta, mas também são os que vêm apresentando crescente participação das motocicletas nas viagens cotidianas, como podemos observar na tabela abaixo:

Tabela 2. Divisão modal por porte de município ${ }^{6}$, em $\%$

\begin{tabular}{c|c|c|c|c|c}
\hline $\begin{array}{c}\text { Meio de } \\
\text { transporte }\end{array}$ & $\begin{array}{c}>\mathbf{1} \\
\text { milhão }\end{array}$ & $\begin{array}{c}\mathbf{5 0 0} \text { mil - } \\
\mathbf{1} \text { milhão }\end{array}$ & $\begin{array}{c}\mathbf{2 5 0} \text { mil - } \\
\mathbf{5 0 0} \mathbf{~ m i l}\end{array}$ & $\begin{array}{l}\mathbf{1 0 0} \text { mil - } \\
\mathbf{2 5 0} \mathbf{~ m i l}\end{array}$ & $\begin{array}{c}\mathbf{6 0} \mathbf{~ m i l ~ - ~} \\
\mathbf{1 0 0} \mathbf{~ m i l}\end{array}$ \\
\hline $\begin{array}{c}\text { Ônibus } \\
\text { metropolitano }\end{array}$ & 2 & 6 & 9 & 9 & 6 \\
\hline $\begin{array}{c}\text { Trilhos (trem e } \\
\text { metrô) }\end{array}$ & 8 & 0 & 0 & 0 & 0 \\
\hline $\begin{array}{c}\text { Transporte } \\
\text { coletivo }\end{array}$ & 10 & 6 & 9 & 9 & 6 \\
\hline Automóvel & 30 & 30 & 25 & 21 & 16 \\
\hline Motocicleta & 3 & 4 & 5 & 6 & 8 \\
\hline $\begin{array}{c}\text { Transporte } \\
\text { individual } \\
\text { motorizado }\end{array}$ & 33 & 34 & 30 & 27 & 24 \\
\hline Bicicleta & 1 & 3 & 5 & 9 & 14 \\
\hline A pé & 34 & 37 & 38 & 39 & 39 \\
\hline Transporte ativo & 35 & 40 & 43 & 48 & 53 \\
\hline Total & 78 & 80 & 82 & 84 & 83 \\
\hline
\end{tabular}

Fonte: SIMOB/ANTP, 2014

Ou seja, além da relação do porte da cidade com a mobilidade ativa, há igualmente maior participação das motocicletas na divisão modal e nos hábitos de locomoção da população quanto menor o município.

Os números de emplacamento de motocicletas nos últimos 16 anos no Brasil, considerando o recorte por porte dos municípios, escancaram o crescimento das motocicletas concentrados, especialmente, nas cidades menores (gráficos 3 e 4).

\footnotetext{
${ }^{6}$ É preciso pontuar que o SIMOB apresenta dados de municípios somente a partir de 60 mil habitantes. Não temos dados, no SIMOB, da divisão modal em municípios menores, que sabemos que têm ampla participação dos meios ativos de deslocamento, crescente participação da motocicleta e do automóvel e quase nenhuma participação de transportes públicos e coletivos.
} 
Gráfico 3. Volume de motocicletas por porte de cidade,

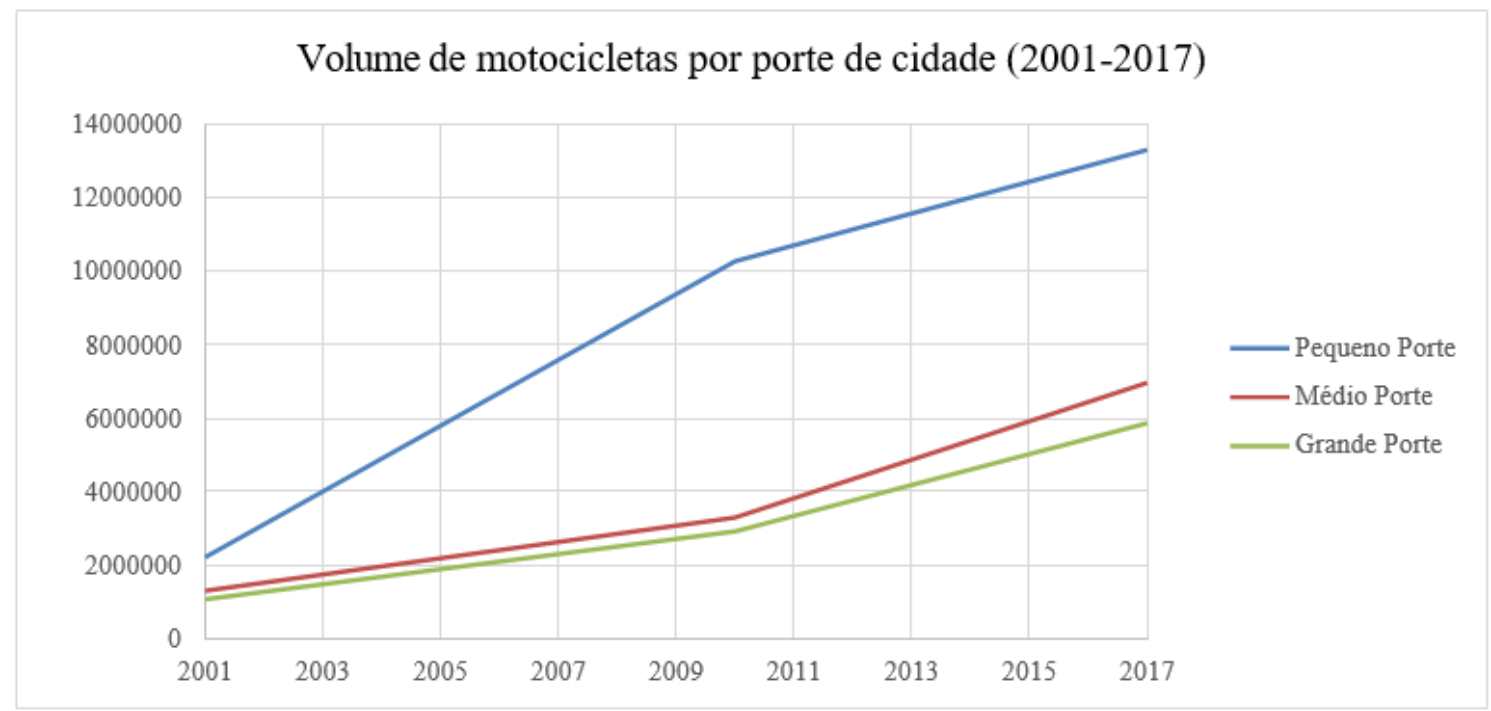

Fontes: elaborado pelos autores a partir de dados DENATRAN, IBGE

Tanto no volume total de motocicletas, quanto na relação proporcional à população (taxa de motorização de motocicletas), os municípios de pequeno porte foram os mais afetados pelas políticas de popularização do consumo e do uso de motocicletas no Brasil.

Gráfico 4. Taxa de motocicletas por mil habitantes por porte te cidade.

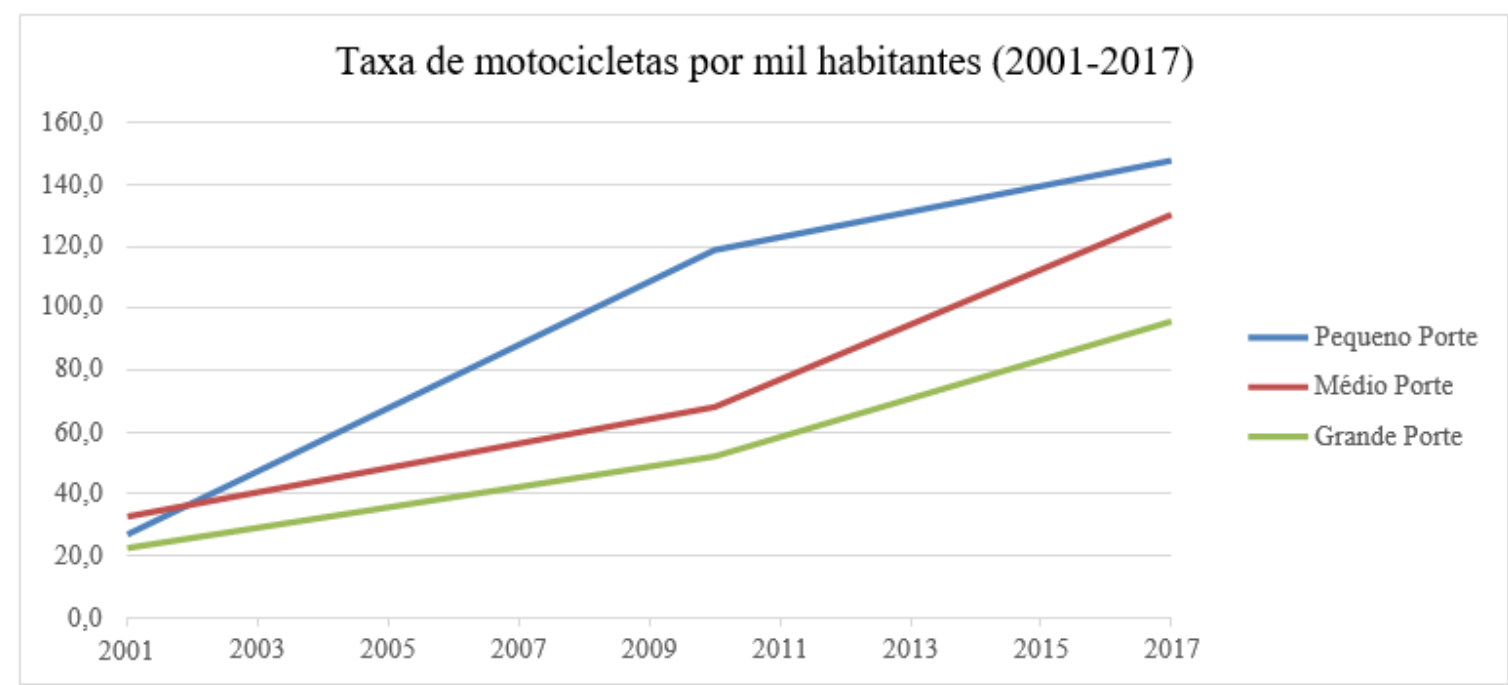

Fontes: elaborado pelos autores a partir de dados DENATRAN e IBGE 
O crescimento das motocicletas nas cidades de pequeno porte tem, potencialmente, transformado o comportamento de viagem (travel behavior) e as relações, percepções e dinâmicas entre as pessoas e o ambiente construído. Entretanto, poucos são os estudos que abordam estes fenômenos e suas possíveis consequências.

Os impactos na saúde pública (Saldiva, 1995), a partir da periculosidade e do crescimento de mortos e feridos em decorrência do aumento da motorização nestas cidades, representam um alerta importante e um caminho possível de análise sobre os impactos desta motorização nas cidades pequenas.

Estudos realizados há décadas no Brasil comprovam que a motocicleta produz quantidade de feridos muito superior à dos demais veículos (Koizumi, 1992). Em pesquisa realizada em 2002 em quatro grandes cidades brasileiras, foi constatado que $7 \%$ dos acidentes de automóvel causavam vítimas de algum tipo, valor que subia para $71 \%$ no caso das motocicletas.

Estudo feito em Caruaru (PE) na região do agreste de Pernambuco (Moura, 2010) com 1.571 vítimas de acidentes viários, mostrou que a motocicleta representava 68,5\% do total de acidentes registrados em 2010. As motocicletas estiveram envolvidas, direta ou indiretamente, em $83 \%$ dos acidentes. $\mathrm{O}$ tipo de acidente mais frequente foi a queda de motocicleta, chegando a $71 \%$ das ocorrências.

Estes números comprovam o que a OMS - Organização Mundial de Saúde (World Health Organization) há mais de uma década vem afirmando em seus relatórios (World report on road traffic injury prevention) acerca de prevenção a acidentes de trânsito.

Uma análise feita pela própria OMS a partir dos dados de mortes de passageiros em todos os meios de transporte disponíveis nos países da União Europeia revelou que os veículos motorizados de duas rodas apresentam, comparativamente, os mais altos níveis de periculosidade e, portanto, de óbitos por quilômetros viajados e por horas viajadas. 
Tabela 3. Mortes por 100 milhões de passageiros-quilômetros vs passageiros-horas viajadas, nos países da União Européia, no período entre 2001-2002.

\begin{tabular}{c|c|c}
\hline & $\begin{array}{c}\text { Mortes por 100 milhões de } \\
\text { passageiros-quilômetro }\end{array}$ & $\begin{array}{c}\text { Mortes por 100 milhões de } \\
\text { passageiros-horas viajadas }\end{array}$ \\
\hline $\begin{array}{c}\text { Veículo motorizado de duas } \\
\text { rodas }\end{array}$ & 13,8 & 440 \\
\hline A pé & 6,4 & 75 \\
\hline Bicicleta & 5,4 & 25 \\
\hline Automóvel & 0,7 & 25 \\
\hline Ônibus & 0,07 & 2 \\
\hline Total (no sistema viário) & 0,95 & 18 \\
\hline Balsa & 0,25 & 8 \\
\hline Aviação & 0,035 & 2 \\
\hline Trilhos & 0,035 & 28 \\
\hline
\end{tabular}

Fonte: elaborado pelos autores a partir de dados World Health Organization (2004)

Uma análise a partir da coleta de dados no Sistema de Informação sobre Mortalidade, do Ministério da Saúde, considerando o recorte das cidades de pequeno porte indicadas como estudo de caso nesta pesquisa exploratória, revelou acentuada tendência de crescimento linear na soma de todos os óbitos que ocorreram nestas cidades entre 2001 e 2016 (Gráfico 5).

Gráfico 5. Óbitos por acidente de transporte, segundo cidades de pequeno porte (2001-2016)

\section{Óbitos por acidente de transporte (2001-2016) - Amostra Cidades Pequeno Porte}

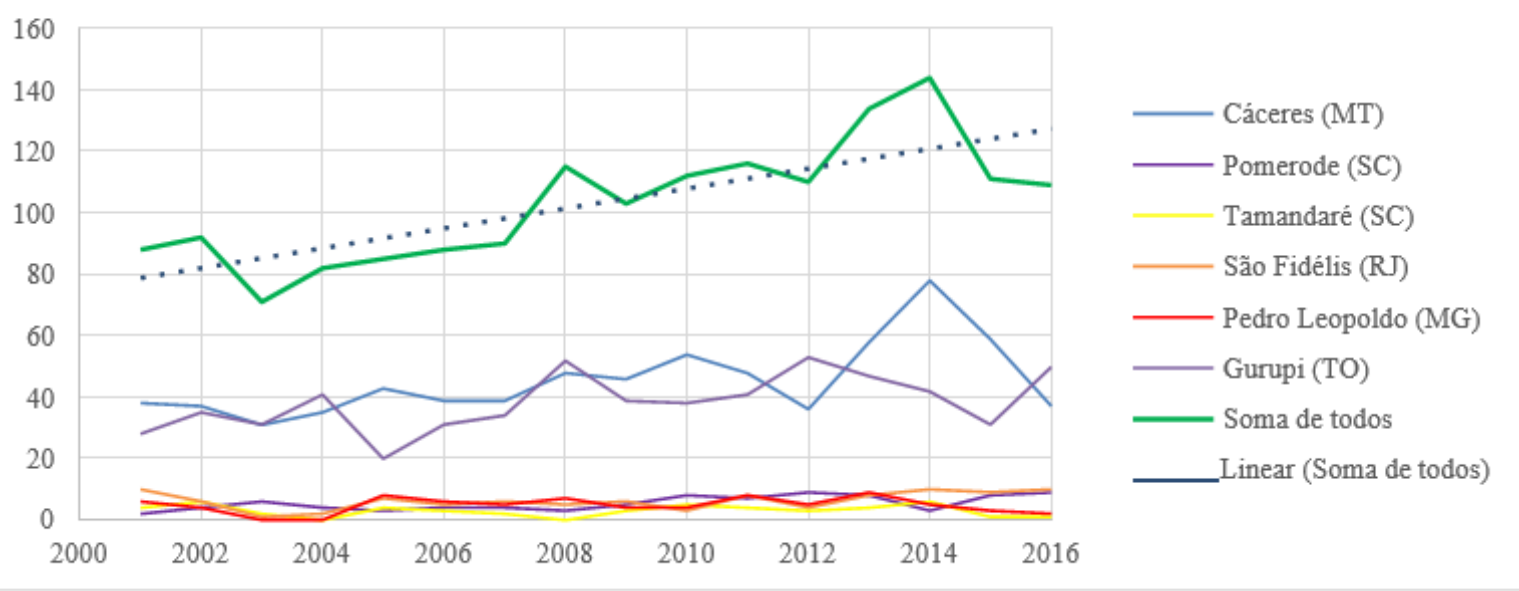

Fonte: MS/SVS/CGIAE - Sistema de Informações sobre Mortalidade 
Para efeito de comparação, analisamos os dados de óbitos por acidade de transporte em uma amostra de cinco municípios de grande porte - São Paulo, Salvador, Belo Horizonte, Curitiba e Belém, no mesmo período entre 2001 e 2016, e os números indicaram tendência linear de queda nos óbitos, oposta à verificada na amostra de cidades de pequeno porte.

Gráfico 6. Óbitos por acidente de transporte, segundo cidades de grande porte (2001-2016)

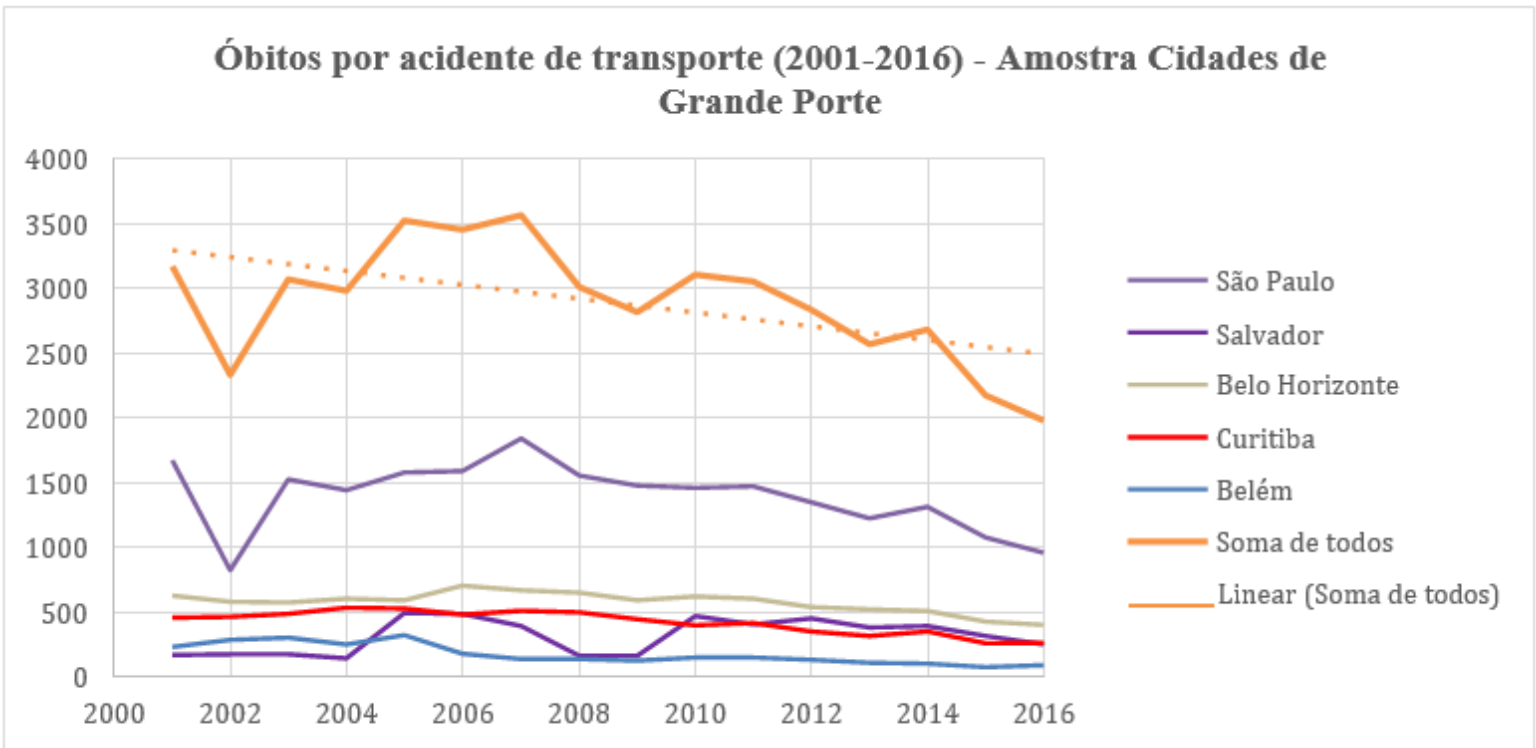

Fonte: MS/SVS/CGIAE - Sistema de Informações sobre Mortalidade

O impacto no número de mortos em motocicletas, segundo Vasconcellos (2013), assumiu a característica de "tragédia social". O número de internações nos hospitais do SUS aumentou de 15 mil em 1998 para 77 mil em 2011 - um aumento da ordem de 404\%. Por terem sido repositório da maior parte das motocicletas emplacadas no país e pela tendência de crescimento no número de óbitos por acidentes de transporte, é possível afirmar que os custos sociais relacionados ao uso da motocicleta, nas cidades de pequeno porte, são altíssimos e merecem especial atenção do poder público e da sociedade.

A Pesquisa Anual por Amostra de Domicílios (PNAD/IBGE, 2008) igualmente nos apresenta dados importantes com relação ao envolvimento em acidentes de trânsito: 2,5\% das pessoas entrevistadas declararam ter se envolvido em um acidente de trânsito nos doze meses anteriores à entrevista. Isto representava, em 2008, 4,8 milhões de pessoas. Os homens tiveram uma participação muito maior que as mulheres, de $70 \%$ contra $30 \%$, e a maior quantidade de vítimas tinha entre 18 e 34 anos de idade. A pesquisa destacou a importância dos eventos no trânsito envolvendo motociclistas nas regiões Norte e Nordeste, 
onde os condutores e ocupantes de motocicletas já ocupavam o primeiro lugar entre as vítimas do trânsito. Considerando a diferença entre as frotas de motocicletas e automóveis e a diferença de severidade nos acidentes, a periculosidade relativa de ferimento ou morte de motociclistas é 15 vezes superior à dos usuários de automóvel.

\section{RESULTADOS E ANÁLISE SOBRE A DIVISÃO MODAL: A PARTICIPAÇÃO DE CADA VEÍCULO NAS VIAGENS DIÁRIAS}

Como vimos, o crescimento das viagens realizadas por veículos motorizados é uma realidade cada dia mais frequente nas cidades brasileiras. Os dados de contagens volumétricas realizados nas dez cidades de pequeno porte estudadas reforçam esta realidade já de intensa motorização, porém também evidenciam uma resiliente cultura de uso de bicicletas, que vai de 7\% de viagens em bicicleta em Gurupi (TO), até $73 \%$ em Tarauacá(AC).

Tabela 4. Distribuição do percentual de divisão modal segundo cidades.

\begin{tabular}{|c|c|c|c|c|c|c|c|c|c|c|}
\hline & \multicolumn{10}{|c|}{ Cidades } \\
\hline Modalidade & $\begin{array}{l}\text { 节 } \\
\text { 总 }\end{array}$ & 总 & 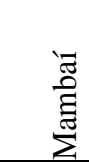 & : & 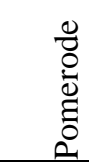 & 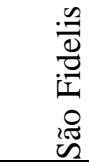 & 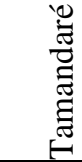 & 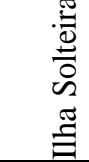 & $\begin{array}{l}\overrightarrow{\hat{z}} \\
\bar{\Xi}\end{array}$ & 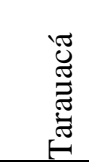 \\
\hline Bicicleta & $29 \%$ & $13 \%$ & $18 \%$ & $14 \%$ & $12 \%$ & $15 \%$ & $17 \%$ & $21 \%$ & $7 \%$ & $73 \%$ \\
\hline Moto & $8 \%$ & $41 \%$ & $17 \%$ & $8 \%$ & $9 \%$ & $32 \%$ & $26 \%$ & $18 \%$ & $34 \%$ & $15 \%$ \\
\hline Automóvel & $43 \%$ & $41 \%$ & $34 \%$ & $41 \%$ & $57 \%$ & $23 \%$ & $31 \%$ & $46 \%$ & $26 \%$ & $5 \%$ \\
\hline Pedestres & $7 \%$ & $3 \%$ & $23 \%$ & $33 \%$ & $12 \%$ & $27 \%$ & $21 \%$ & $10 \%$ & $27 \%$ & $4 \%$ \\
\hline Caminhão & $7 \%$ & $1 \%$ & $3 \%$ & $1 \%$ & $6 \%$ & $1 \%$ & $1 \%$ & $1 \%$ & $1 \%$ & $1 \%$ \\
\hline Ônibus & $3 \%$ & $0 \%$ & $1 \%$ & $1 \%$ & $1 \%$ & $1 \%$ & $1 \%$ & $1 \%$ & $0 \%$ & $0 \%$ \\
\hline Outros & $3 \%$ & $1 \%$ & $5 \%$ & $2 \%$ & $4 \%$ & $1 \%$ & $3 \%$ & $3 \%$ & $6 \%$ & $1 \%$ \\
\hline
\end{tabular}

Fonte: Contagem veicular (2017), coordenada pelos autores 
A participação dos automóveis na divisão modal das viagens está relacionada tanto aos aspectos socioeconômicos, quanto ao porte das cidades. Tarauacá (40.024 hab) e Pomerode (32.334 hab), por exemplo, apesar de terem porte similar, têm percentuais antagônicos de uso de automóvel: enquanto Pomerode tem $62 \%$ de viagens feitas por automóvel em um dos pontos de contagem, em Tarauacá este percentual é de apenas 5\%. Pomerode tem mais de 800 veículos motorizados para cada 1 mil habitantes5, enquanto Tarauacá tem 107 veículos motorizados para cada 1 mil habitantes. Enquanto Tarauacá tem PIB per capita de R $10.285,626$, Pomerode tem PIB per capita cinco vezes superior, alcançando $\mathrm{R} \$ 56.684,06$ - um dos mais altos do país.

Observando o crescimento da motorização nas dez cidades (Tabela 5), verificamos que as regiões norte, nordeste e centro-oeste foram as que percentualmente mais cresceram no número de automóveis e motocicletas entre 2001 e 2017, ainda que não apresentem as mais altas taxas de motorização (veículos motorizados por habitante). As regiões sudeste e sul tiveram crescimento menos expressivo, porém são as que apresentam as mais altas taxas de motorização - o que é explicado, parcialmente, pela concentração de renda nestas regiões e pelo fato de que o acesso e o incentivo à aquisição de veículos motorizados teve início há muitas décadas nestas regiões.

Tabela 5. Crescimento da motorização entre 2001 e 2017

\begin{tabular}{|c|c|c|c|c|c|c|}
\hline & & & \multicolumn{4}{|c|}{ Veículos motorizados } \\
\hline Região & UF & Cidade & $\mathbf{2 0 0 1}$ & $\mathbf{2 0 1 7}$ & $\begin{array}{c}\text { Crescimento } \\
(\mathbf{2 0 0 1} \text { a 2017) }\end{array}$ & $\begin{array}{c}\text { Por mil } \\
\text { habitantes em } \\
\mathbf{2 0 1 7}\end{array}$ \\
\hline $\begin{array}{c}\text { Centro- } \\
\text { Oeste }\end{array}$ & GO & Mambaí & 162 & 2214 & $\begin{array}{c}1266,67 \\
\%\end{array}$ & 267,6822633 \\
\hline Norte & AC & Tarauacá & 424 & 4306 & $915,57 \%$ & 107,5854487 \\
\hline Nordeste & PE & Tamandaré & 430 & 4119 & $857,91 \%$ & 178,3116883 \\
\hline Sul & PR & Antonina & 1006 & 5105 & $407,46 \%$ & 262,8733265 \\
\hline Norte & TO & Gurupi & 13026 & 58268 & $347,32 \%$ & 681,3137986 \\
\hline $\begin{array}{c}\text { Centro- } \\
\text { Oeste }\end{array}$ & MT & Cáceres & 11315 & 46282 & $309,03 \%$ & 507,0833014 \\
\hline Sudeste & RJ & São Fidelis & 5021 & 16327 & $225,17 \%$ & 433,2033219 \\
\hline Sudeste & MG & $\begin{array}{c}\text { Pedro } \\
\text { Leopoldo }\end{array}$ & 11210 & 31099 & $177,42 \%$ & 487,1626173 \\
\hline Sudeste & SP & Ilha Solteira & 7564 & 17908 & $136,75 \%$ & 674,7550867 \\
\hline Sul & SC & Pomerode & 10998 & 25876 & $135,28 \%$ & 800,2721593 \\
\hline
\end{tabular}

Fonte: DENATRAN (2001 e 2017) 
Tomemos como exemplo as cidades de Cáceres (MT), Tamandaré (PE) e Pedro Leopoldo (MG), uma em cada região do país. A cidade matogrossense, que faz divisa com a Bolívia, viu explodir sua frota de motocicletas entre 2001 e 2017 saltando de 4,9 mil para 24,6 mil motocicletas, motonetas e ciclomotores. Uma pesquisa de origem e destino realizada em 2004 (Ferreira, 2004) revelou que 72,54\% das viagens em Cáceres eram realizadas por bicicletas, já motocicletas respondiam por apenas 7,21\% das viagens e automóveis, por 4,1\%. Treze anos depois, em 2017, os dados de contagens veiculares realizadas em dois pontos da cidade revelaram que a bicicleta representou, em média, $13 \%$ das viagens nas vias analisadas - uma redução de $82 \%$ nas viagens de bicicleta, em comparação com a pesquisa O/D de 2004 -, enquanto motocicletas foram espantosos $41 \%$ das viagens (número seis vezes superior ao índice de 2004).

Em Tamandaré, cidade do litoral sul de Pernambuco e com profunda tradição de uso de bicicleta, a frota de motocicletas e automóveis também cresceu intensamente. Dados de contagem veicular realizada na principal via da cidade em 2017 revelaram participação das bicicletas em $17 \%$ das viagens, enquanto automóveis foram $31 \%$ e motocicletas, $26 \%$.

Em Pedro Leopoldo, cidade mineira localizada na região metropolitana de Belo Horizonte, a pesquisa de Origem e Destino de 2002 (BHTrans, 2002 e 2012) revelou que as bicicletas tinham participação em 17,2\% das viagens, enquanto viagens a pé eram $36,1 \%$, automóveis $21 \%$, transporte coletivo, $15,5 \%$ e motocicletas, 1,7\%. Dez anos depois, em 2012, a mesma pesquisa replicada revelou que as viagens de bicicleta caíram pela metade e totalizaram $8,6 \%$ das viagens, enquanto as viagens a pé reduziram alguns pontos percentuais e alcançaram 33,2\%. Já as viagens feitas de automóvel cresceram de 21 para $26,2 \%$, e de motocicletas, de 1,7 para $5 \%$ das viagens. O transporte coletivo também encolheu e foi de 15,5 para 13,4\% das viagens.

\section{CARACTERIZAÇÃO E PERFIL DE CICLISTAS}

Contagens volumétricas e de caracterização podem ser bastante reveladoras para se aprofundar o conhecimento de uma realidade a partir da mobilidade por bicicletas. A tabela abaixo (Tabela 6), criada a partir das contagens realizadas nas cidades estudadas, carrega narrativas importantes e que merecem alguns destaques: 
Tabela 6. Contagem volumétrica e caracterização de ciclistas

\begin{tabular}{|c|c|c|c|c|c|c|c|c|c|c|}
\hline \multirow[b]{2}{*}{ Variável } & \multicolumn{10}{|c|}{ Cidades } \\
\hline & 㞼 & : & 疋 & 을 & 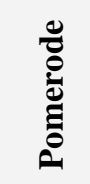 & 赵 & & 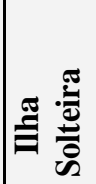 & 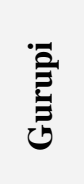 & \\
\hline $\begin{array}{l}\text { Total de viagens } \\
\text { de bicicletas na } \\
\text { principal via da } \\
\text { cidade }\end{array}$ & 2.477 & 1.741 & 643 & 1.475 & 1.419 & 1.678 & 1.341 & 4.906 & 911 & 5.938 \\
\hline Mulheres & $30 \%$ & $38 \%$ & $29 \%$ & $30 \%$ & $40 \%$ & $33 \%$ & $39 \%$ & $41 \%$ & $29 \%$ & $34 \%$ \\
\hline Homens & $70 \%$ & $62 \%$ & $71 \%$ & $70 \%$ & $60 \%$ & $67 \%$ & $61 \%$ & $59 \%$ & $71 \%$ & $66 \%$ \\
\hline Uso de Calçada & $11 \%$ & $2 \%$ & $1 \%$ & $4 \%$ & $1 \%$ & $1 \%$ & $2 \%$ & $22 \%$ & $4 \%$ & $0 \%$ \\
\hline $\begin{array}{l}\text { Uso de } \\
\text { Contramão }\end{array}$ & $56 \%$ & $9 \%$ & $7 \%$ & $42 \%$ & $0 \%$ & $0 \%$ & $5 \%$ & $3 \%$ & $5 \%$ & $0 \%$ \\
\hline Carga/Serviço & $3 \%$ & $1 \%$ & $3 \%$ & $4 \%$ & $0 \%$ & $2 \%$ & $10 \%$ & $0 \%$ & $2 \%$ & $2 \%$ \\
\hline Esporte & $0 \%$ & $0 \%$ & $3 \%$ & $0 \%$ & $3 \%$ & $0 \%$ & $0 \%$ & $0 \%$ & $1 \%$ & $0 \%$ \\
\hline Bicicletas comuns & $97 \%$ & $99 \%$ & $94 \%$ & $96 \%$ & $96 \%$ & $98 \%$ & $90 \%$ & $99 \%$ & $97 \%$ & $98 \%$ \\
\hline $\begin{array}{l}\text { Menores de } 16 \\
\text { anos }\end{array}$ & $9 \%$ & $11 \%$ & $23 \%$ & $9 \%$ & $6 \%$ & $4 \%$ & $11 \%$ & $13 \%$ & $9 \%$ & $16 \%$ \\
\hline $\begin{array}{l}\text { Maiores de } 60 \\
\text { anos }\end{array}$ & $11 \%$ & $6 \%$ & $9 \%$ & $16 \%$ & $10 \%$ & $7 \%$ & $5 \%$ & $9 \%$ & $3 \%$ & $1 \%$ \\
\hline Adultos & $80 \%$ & $83 \%$ & $67 \%$ & $75 \%$ & $84 \%$ & $89 \%$ & $84 \%$ & $78 \%$ & $89 \%$ & $83 \%$ \\
\hline $\begin{array}{l}\text { Com } \\
\text { carona/garupa }\end{array}$ & $7 \%$ & $6 \%$ & $6 \%$ & $4 \%$ & $5 \%$ & $5 \%$ & $10 \%$ & $3 \%$ & $3 \%$ & $15 \%$ \\
\hline Com capacete & $0 \%$ & $0 \%$ & $2 \%$ & $0 \%$ & $1 \%$ & $0 \%$ & $0 \%$ & $0 \%$ & $1 \%$ & $0 \%$ \\
\hline
\end{tabular}

Fonte: Contagem veicular (2017), coordenada pelos autores

Em média 34,9\% de todas as pessoas pedalando, nas cidades de pequeno porte estudadas, são mulheres. Ilha Solteira e Pomerode, cada uma com $40 \%$ ou mais de viagens de bicicleta realizadas por mulheres, destacaram-se. Estes dados são ainda mais surpreendentes e reveladores se compararmos com a média de $7 \%$ de mulheres ciclistas ${ }^{7}$ nas grandes cidades brasileiras. Cabe o desenvolvimento de investigações para melhor compreensão do porque o share de mulheres ciclistas em cidades de pequeno porte é representativamente maior do que em cidades de médio e grande porte. O uso da calçada por ciclistas oscilou sensivelmente entre as cidades estudadas. Isto se deve a características pontuais dos locais de contagem, como é o caso de Ilha Solteira, que

\footnotetext{
${ }^{7}$ Média entre 40 contagens de ciclistas realizadas por associações locais, em capitais e grandes cidades, entre 2008 e 2015 (Freitas, 2015).
} 
apresentou $22 \%$ de uso de calçada por ciclistas. O uso da pista de rolamento por ciclistas, no entanto, é o mais difundido, oscilando entre 90 e 100\% em todas as cidades. Já o uso da contramão por ciclistas, assim como a calçada, está também associado a condicionantes locais e pontuais. Isto é, trata-se de um subterfúgio, um recurso acessado por ciclistas para situações em que o desenho urbano (especialmente o viário) está em desacordo com as características do deslocamento ativo. Antonina e Pedro Leopoldo apresentaram os maiores índices de uso de contramão, com 56 e $42 \%$, respectivamente.

Entre todas as bicicletas contabilizadas, 96,4\% eram bicicletas comuns (urbanas e híbridas) utilizadas como meio de transporte. Bicicletas cargueiras e bicicletas para a prática esportiva apresentaram baixo uso em comparação com o total de bicicletas. No entanto, algumas cidades revelaram dados interessantes como Tamandaré, com 10\% de bicicletas cargueiras e Mambaí, com 3\% de bicicletas para esporte. A pesquisa de perfil, que será revelada a seguir, aprofundará os aspecto sobre ciclistas e suas motivações para uso de bicicleta.

Cidades de pequeno porte mantém viva a utilização da garupa da bicicleta, seja por crianças, jovens ou mesmo por adultos. Em Tarauacá, por exemplo, em 15\% de todas as bicicletas contabilizadas havia uma pessoa na garupa. Em Tamandaré este índice foi de 10\%. Já o uso de capacete é praticamente inexistente nas cidades de pequeno porte, que oscilam entre 0 e $1 \%$ de ciclistas pedalando com o acessório. Mambaí (GO) é a cidade que apresentou o mais alto índice: $2 \%$ de ciclistas com capacete.

Durante os meses de Setembro a Novembro de 2017, pesquisadores foram a campo para entrevistar ciclistas em seus deslocamentos, durante a semana, em todas as dez cidades aqui retratadas. Foram realizadas 2109 entrevistas nas dez cidades, uma amostra importante para uma pesquisa exploratória sobre o uso de bicicleta em cidades pequenas. A tabela abaixo (Tabela 7) revela a demografia e o número de entrevistas realizadas em cada cidade: 
Tabela 7. Entrevistas realizadas em relação à população

\begin{tabular}{|c|c|c|}
\hline Cidade & Populaçã $^{\mathbf{8}}$ & Quantidade de entrevistas realizadas $^{\circ}$ \\
\hline Mambaí (GO) & 8.271 & 58 \\
\hline Antonina (PR) & 19.420 & 300 \\
\hline Tamandaré (PE) & 23.100 & 274 \\
\hline Ilha Solteira (SP) & 26.540 & 183 \\
\hline Pomerode (SC) & 32.334 & 289 \\
\hline São Fidelis (RJ) & 37.689 & 300 \\
\hline Tarauacá (AC) & 40.024 & 147 \\
\hline Pedro Leopoldo (MG) & 63.837 & 90 \\
\hline Gurupi (TO) & 85.523 & 282 \\
\hline Cáceres(MT) & 91.271 & 186 \\
\hline
\end{tabular}

O questionário da pesquisa de perfil contempla desde questões sobre o perfil da pessoa, como renda, idade, escolaridade; até questões mais opinativas e relacionadas ao uso de bicicleta, como frequência de uso, motivação para começar a pedalar, principais problemas no deslocamento, entre outras. Considerando o caráter exploratório desta pesquisa, podemos aferir a partir dos resultados encontrados nas dez cidades de pequeno porte o seguinte:

Mais de $90 \%$ dos ciclistas têm até o ensino médio completo. Mambaí (GO) tem quase metade (43\%) de ciclistas que responderam não ter instrução. Em Antonina (PR), mais da metade (52\%) têm até o ensino fundamental completo. Praticamente 2/3 de todos os ciclistas ganham entre 0 e 2 salários mínimos. A renda média per capita é de R \$ 1.548,67. Em Mambaí, $40 \%$ dos ciclistas declararam não ter renda. Em São Fidelis (RJ), 38\% responderam ganhar até 1 salário mínimo.

Mais de 2/3 (64,6\%) dos ciclistas se autodeclararam pardos ou pretos. Brancos somaram $33,5 \%$, amarelos foram 2,20\% e indígenas, $1 \%$ (Tabela 8). Pomerode (SC), é a cidade cujo resultado destoa das demais, com $66 \%$ dos ciclistas que se autodeclararam brancos e $9 \%$ pretos. A maior população autodeclarada preta, entre as cidades, é Gurupi (TO) com $29 \%$ de pretos.

Na comparação com os dados de cor/raça do Censo de 2010 (IBGE), o perfil dos ciclistas nas cidades estudadas aponta para uma diversidade maior do que os dados gerais da população nestas cidades. Com exceção dos autodeclarados pardos, cujo índice praticamente não se alterou, em média os ciclistas nestas cidades são mais pretos (três vezes mais) do que na cidade 
como um todo, são quase $11 \%$ menos brancos, apresentam o dobro de pessoas que se autodeclaram amarelas e também o dobro de indígenas. Individualmente, nesta comparação com o Censo 2010, destacam-se Tamandaré (PE) com quatro vezes mais ciclistas autodeclarados pretos do que na cidade como um todo ( $20 \%$ entre ciclistas e 5,13\% na cidade como um todo); Pomerode (SC) com 9\% de ciclistas pretos, enquanto que na cidade este índice é de $0,74 \%$; Ilha Solteira (SP) $\operatorname{com} 2 \%$ de ciclistas autodeclarados indígenas, enquanto que na cidade este índice é de 0,21\%; Mambaí (GO) com 5\% de ciclistas autodeclarados amarelos, enquanto que na cidade este índice é de $0,10 \%$.

Tabela 8. Cor/Etnia autodeclarada pelos ciclistas entrevistados em comparação com o Censo 2010

\begin{tabular}{|c|c|c|c|c|}
\hline \multirow{7}{*}{ 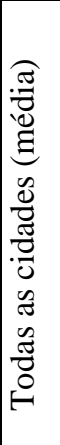 } & \multirow{2}{*}{ Cor/Etnia } & \multicolumn{2}{|c|}{ IBGE 2010} & \multirow{2}{*}{$\begin{array}{c}\text { Perfil Ciclistas } \\
\%\end{array}$} \\
\hline & & Total & $\%$ & \\
\hline & Branca & 158162 & 44.09 & 33.50 \\
\hline & Preta & 27705 & 5.76 & 16.30 \\
\hline & Amarela & 4759 & 1.12 & 2.20 \\
\hline & Parda & 203280 & 48.50 & 46.80 \\
\hline & Indígena & 1964 & 0.53 & 1.00 \\
\hline
\end{tabular}

Fontes: Pesquisa de Perfil de Ciclistas (2017) e IBGE

Com relação ao tempo gasto na principal viagem realizada por bicicleta, destacam-se as curtas e plenamente acessíveis distâncias. Para 63,6\% das pessoas entrevistadas em todas as cidades, as viagens de bicicleta não superam 20 minutos de pedalada. Em Tamandaré (PE), $51 \%$ das principais viagens de bicicleta não superam 15 minutos de pedalada. Em Pomerode (SC), apenas $15 \%$ afirmaram que sua principal viagem de bicicleta tem duração superior a 45 minutos.

A pergunta sobre motivação para começar a pedalar como meio de transporte revela, mais do que qualquer outra questão, o potencial da bicicleta como solução inclusiva para a mobilidade urbana. A pesquisa de perfil de ciclistas revelou que mais de $1 / 3(34,3 \%)$ dos ciclistas entrevistados disseram que começaram a pedalar porque a bicicleta "é mais rápida e prática". Para 27,3\%, o motivo principal foi a economia deste meio de transporte. Para outros $22 \%$ dos ciclistas, o principal motivo foi a saúde. Apenas 3,14\% responderam que o principal motivo é porque a bicicleta é um veículo "ambientalmente correto" e 13,1\% apresentaram outros motivos. Este resultado é significativo e precisa ser considerado por gestores públicos e tomadores de decisão no desenvolvimento de políticas de promoção da mobilidade ativa e 
implantação de infraestrutura cicloviária.

Sabe-se, contudo, que a escolha - feita por indivíduos - pelo meio de transporte a ser utilizado se dá a partir de uma pluralidade de características e valores multifacetados individuais, socioculturais, do ambiente construído e das políticas públicas e do ambiente natural (Diagrama 1).

Diagrama 1. Determinantes do comportamento de viagem (travel behavior)

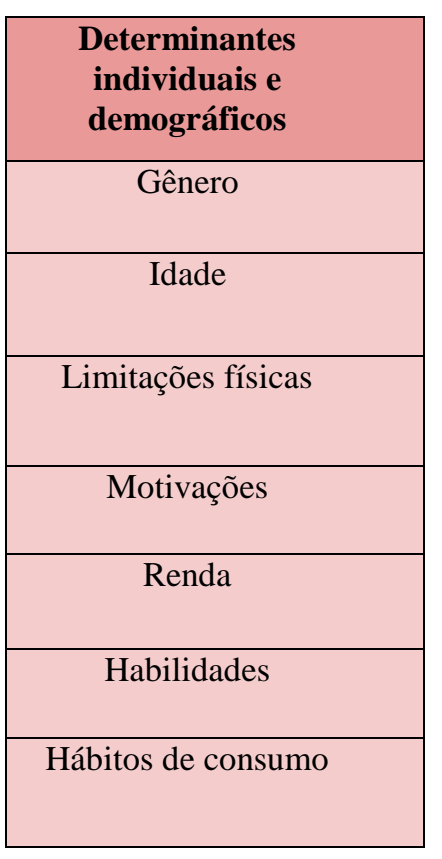

Fonte: elaboração própria

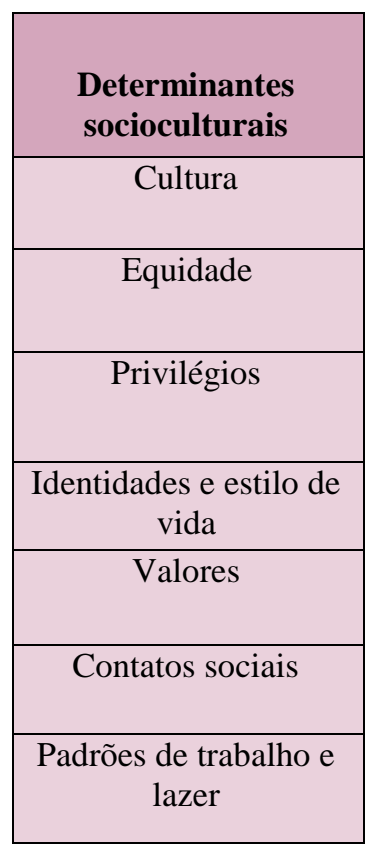

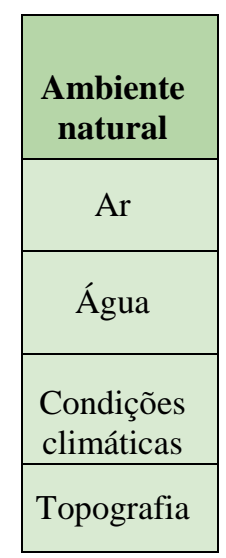

Centralidades e subcentros

Locais de compras

Políticas de incentivo e/ou desestímulo

O enredo de determinantes, exemplificado no diagrama acima, revela caminhos interessantes para uma compreensão mais complexa sobre a resiliência do uso de bicicletas nas cidades de pequeno porte, uma vez que variáveis como renda, baixa oferta de transporte público, valores culturais e dentitários ${ }^{8}$, condições favoráveis do ambiente natural e o uso do solo - combinado com o desenho urbano que promove deslocamentos mais curtos , são indispensáveis para esta compreensão.

A frequência de uso de bicicleta revela, ainda, a importância - e por que não, a dependência - deste veículo para o cotidiano dos ciclistas. Em média, 86,75\% dos ciclistas, em

\footnotetext{
${ }^{8}$ De acordo com Heinen (2016), cuja pesquisa na Holanda aprofundou questões relativas à identidade social e hábitos de locomoção (travel behavior), "para todos os meios de transporte analisados (carro, bicicleta e mobilidade a pé), descobriu- se que quanto mais um indivíduo se identificava como sendo um usuário de um determinado meio de transporte, maior era sua capacidade de resistir a reduzir a utilização deste meio de transporte".
} 
todas as cidades, usam a bicicleta cinco dias ou mais na semana. Para 68,12\%, a bicicleta é o principal veículo para todos os sete dias da semana. Em Tarauacá (AC), 86\% dos ciclistas afirmaram usar a bicicleta durante os 7 dias da semana e em Tamandaré (PE) e Ilha Solteira (SP), o índice de pessoas usando a bicicleta todos os dias da semana foi de $74 \%$ e $77 \%$, respectivamente.

Combinadas com a frequência, as respostas sobre há quanto tempo ciclistas utilizam a bicicleta como meio de transporte revelou como a bicicleta é utilizada pela população desde muito cedo. Quase $82 \%$ dos ciclistas usam a bicicleta como meio de transporte há mais de $5 \operatorname{anos}^{910}$. Em Tamandaré (PE), esse índice foi de $95 \%$.

A maioria absoluta ( $83 \%)$ dos ciclistas, nas cidades pequenas, não combina a bicicleta com nenhum outro meio de transporte em seus deslocamentos. Cáceres (MT) e Gurupi (TO) apresentaram resultados destoantes, com $45 \%$ de ciclistas combinando viagens com outros meios de transporte, especialmente com motocicletas ${ }^{11}$. Em Pedro Leopoldo (MG), dos $18 \%$ de ciclistas que fazem intermodalidade, $63 \%$ combinam a bicicleta com automóveis e 19\% com ônibus. Cabe ressaltar, ainda, que as cidades de menor porte têm uma mancha urbana reduzida e, em geral, uma rede de transporte público ineficiente (ou, na maioria dos casos, inexistente), que não atende boa parcela da população. Estes fatores influenciam diretamente nos resultados pois há baixo potencial de intermodalidade considerando a oferta atual de transporte público.

\section{CONSIDERAÇÕES FINAIS}

O presente artigo partiu de uma ampla pesquisa exploratória realizada pelos autores em dez cidades de até 100 mil habitantes e buscou destacar os atributos sobre a cultura da bicicleta nestas cidades, reconhecendo seu caráter inclusivo e revelando uma dinâmica em curso que vem modificando sensivelmente esta realidade: o crescimento da motorização, especialmente da circulação de motocicletas, na paisagem urbana destas cidades.

Olhares mais atentos e aprofundados poderão nos revelar de que maneira esta crescente motorização vem impactando o uso de bicicletas nas cidades brasileiras, quais são as consequências (positivas e negativas) deste fenômeno e as variáveis associadas a esta migração modal a partir de modelagens de comportamento de viagem.

\footnotetext{
${ }^{9}$ Ainda que nas grandes cidades haja um contingente grande de ciclistas recentes, como pode ser observado nos resultados da pesquisa de perfil de ciclistas divulgada em 2015 pela ONG Transporte Ativo, nas cidades pequenas a própria pergunta já era motivo de espanto, pois a cultura de uso de bicicleta está presente desde a primeira infância.
} 
Uma primeira leitura dos dados da pesquisa de perfil realizada nas dez cidades estudadas, combinados com o diagrama de determinantes do comportamento de viagem, já apontam para valores importantes que devem ser estimulados e promovidos em favor da manutenção e do crescimento da mobilidade ativa.

O crescimento da motorização e dos acidentes fatais em decorrência do crescimento especialmente de motocicletas ${ }^{10}$, nas cidades de pequeno porte, indicam um cenário em que não apenas a mobilidade ativa está sendo impactada e ameaçada, mas a qualidade de vida em si associada aos altos custos sociais pelo aumento da violência no trânsito. O que fazer para frear ou reverter este quadro pode ser uma questão igualmente relevante frente o novo paradigma da mobilidade sustentável (Bannister, 2008).

Cidades como Cáceres (MT), popularmente conhecida como "Capital Nacional do Ciclista" 11 , que viu o uso de bicicleta encolher de 72,5\% de viagens, em 2004, para $18 \%$ em 2017; ou Mambaí (GO), cidade de apenas 8,2 mil habitantes, que viu sua taxa de motorização crescer 699\% entre 2001 e 2017, são alguns dos exemplos concretos que ilustram a urgência do tema. São desafios e oportunidades para serem aprofundadas em outras investigações e também por gestores públicos e planejadores.

Ainda, a existência e manutenção de cidades com alto índice de uso de bicicletas é de suma importância para o Brasil, pois elas escancaram com pragmatismo todos os benefícios individuais, sociais e ambientais do uso de bicicleta, revelando-a cada dia mais viável para a mobilidade de cidades em todo o país. Mesmo as cidades de grande porte, muitas com extenso território, podem se basear nas cidades de pequeno porte, pois também nelas a maior parte dos deslocamentos ocorre em curtas e médias distâncias - dentro de um bairro ou entre bairros vizinhos -, seja para o trabalho, para o estudo ou para as compras.

Igualmente a pesquisa de perfil de ciclistas transpareceu esta importância do uso de bicicletas para o acesso e o direito à cidade, especialmente por minorias e pessoas de mais baixa renda, escolaridade e que, certamente, hoje não têm ofertados pelo poder público outros modos para viabilizar seus deslocamentos cotidianos.

Um Brasil em transição se evidencia nas cidades de pequeno porte, onde a tradição de uso da bicicleta ainda se mantém resiliente, mas vem rapidamente perdendo espaço para a modernidade motorizada. São mudanças sensíveis nas dinâmicas dos espaços urbanos,

\footnotetext{
${ }^{10}$ Suspeitamos que tenha ocorrido um equívoco de interpretação desta pergunta nas cidades de Cáceres e Gurupi. $\mathrm{O}$ alto índice de intermodalidade entre bicicleta e motocicleta indica que as pessoas entrevistas interpretaram a questão como sendo "qual outro você utiliza, além da bicicleta" e não "qual outra modalidade você usa para completar a viagem".

${ }^{11}$ Assim está escrito, até hoje, em uma placa na entrada da cidade.
} 
revelando-se como uma questão de urgência e um convite para pesquisadores de múltiplas áreas, interessados nas fricções entre a mobilidade, a paisagem e a forma urbanas e as teorias do travel behavior (comportamento de viagem).

Por fim, considerando que as bicicletas se tornaram populares no Brasil a partir do final da década de $1940^{12}$, e considerando que a popularização da motocicleta é um fenômeno recente - entre 2001 e 2016, o número de motos saltou de 4,5 milhões para mais de 25 milhões, uma variação que supera $500 \%^{13}$, podemos aferir, com base na leitura dos dados apresentados ao longo do artigo, que a motorização vem impactando diretamente a cultura da bicicleta nas cidades brasileiras, especialmente onde ela é mais consolidada desde os anos 1950: nas cidades de pequeno porte.

\footnotetext{
12 Até quase a década de 1950 as bicicletas, no Brasil, eram acessíveis apenas às camadas mais ricas da população, que detinham meios e recursos para importá-las principalmente da Europa (Guth, D. 2016).

${ }^{13}$ Neste período, a frota de motocicletas nas regiões Norte e Nordeste, por exemplo, aumentou 641,5 e 639\%, respectivamente.
} 


\section{REFERENCIAS}

ANTP - Associação Nacional de Transportes Públicos. Sistema de Informações da Mobilidade Urbana Relatório Geral 2014. São Paulo, ANTP, Julho/2016.

BANNISTER, David. Transport Policy. The sustainable mobility paradigm. 15:73-80. Disponível em: <https://doi.org/10.1016/j.tranpol.2007.10.005> Acessado em: 11 de Fevereiro de 2019.

BOSI, Alfredo. A origem da palavra cultura. Disponível em: https://pandugiha.wordpress.com/2008/11/24/alfredo-bosi-a-origem-da-palavra-cultura/ Acessado em: $14 \mathrm{de}$ Fevereiro de 2019.

COX, Peter. Cycling cultures. Chester, UK: University of Chester Press, 2015.

DENATRAN - Departamento Nacional de Trânsito. Relatórios de Gestão. Brasília, anos 2001 a 20017.

FREITAS, Ana. Quem são as mulheres que andam de bicicleta em São Paulo. Disponível em:

<https://www.nexojornal.com.br/expresso/2016/09/22/Quem-s\%C3\%A3o-as-mulheres-que- andamde-bicicleta-em-S\%C3\%A3o-Paulo > Acessado em: 20 de Janeiro de 2019.

GOODMAN, David. What is bike culture? Disponível em:https://cityroom.blogs.nytimes.com/2010/03/30/whatis-bike-culture/> Acessado em: 26 de Janeiro de 2019.

GUTH, Daniel. Migração modal: por que estamos perdendo ciclistas diariamente. In: Mobilidade por Bicicleta no Brasil. Prourb, UFRJ. p. 239-264. Rio de Janeiro, 2016.

HEINEN, Eva. Identity and travel behaviour: A crosssectional study on commute mode choice and intention to change. In: Transportation Research Part F 43, 238- 253. Disponível em: <https://doi.org/10.1016/j.trf.2016.10.016> Acessado em: 10 de Fevereiro de 2019.

IBGE - Instituto Brasileiro de Geografia e Estatística. IBGE Cidades. Disponível em: <https://cidades.ibge.gov.br/brasil> Acessado em: 10 de Fevereiro de 2019.

Censo populacional do Brasil. Brasília, 2000. Disponível em:

<www.ibge.gov.br> Acessado em: 08 de Fevereiro de 2019.

KOIZUMI, Maria Sumie. Acidentes de motocicleta no Município de São Paulo, SP, Brasil. 2. Análise da mortalidade. Revista de Saúde Pública no 6, vol. 19. São Paulo, dez/1985.

MINAS Gerais, Secretaria Extraordinária de Gestão Metropolitana, Agência de Desenvolvimento da Região Metropolitana de Belo Horizonte (2013). Pesquisa Origem e Destino 2011-2012 - Relatório completo. Belo Horizonte, Brasil.

MS - Ministério da Saúde. Sistema de Informação sobre Mortalidade (SIM). Disponível em: < NESPOLI, Luiz Carlos Mantovani (Org.). Mobilidade humana para um Brasil urbano. São Paulo:

ANTP - Associação Nacional de Transportes Públicos, 2017.

RODRIGUES, Juciano Martins (2015). Estado da motorização individual no Brasil - relatório 2015. Disponível em:

〈http://www.observatoriodasmetropoles.net/download/automoveis_e_motos2015.pdf > Acessado em: 10 de Fevereiro de 2019.

SALDIVA, P. H. et al (1995). Air pollution and mortality in elderly people: a time-series study in São Paulo, Brazil. Archives of Environmental Health: An International Journal, 50(2), 159-163.

SOARES, André, GUTH, Daniel (Org.). O Brasil que pedala: a cultura da bicicleta nas cidades pequenas. Rio de Janeiro: Ed. Jaguatirica, 2018. 
VASCONCELLOS, Eduardo A. Risco no trânsito, omissão e calamidade [livro eletrônico] : impactos do incentivo à motocicleta no Brasil / Eduardo A. Vasconcellos. -- São Paulo : Ed. do Autor, 2013. Disponível em: 〈http://www.mobilize.org.br/midias/pesquisas/risco-no-transito- $\quad$ omissao-e-calamidade.pdf> Acessado em: 12 de Fevereiro de 2019.

WHO - World Health Organization. World report on road traffic injury prevention. Genebra, Suíça, 2004.

VREDIN-JOHANSSON, M., Heldt, T. and Johansson, P. (2006). The effects of attitudes and personality traits on mode choice. Transportation Research 40A, 507-525. 